\title{
Experience and early results of second reoperations for coronary artery disease
}

\author{
Should patent vein grafts be replaced during reoperation?
}

Reoperation for coronary artery disease has become a routine procedure; however, a second reoperation is exceptional. In this report we describe our experience with 16 patients undergoing a second reoperation for coronary atherosclerosis. The absence of operative mortality is certainly related to the patient selection. The number of patients is still too small to draw major conclusions. Striking, however, is that the first reoperation was usually done for angina because of progression of atherosclerosis in the native coronary system and the second reoperation was done because of graft failure. This experience supports the idea that the replacement of old, even patent, venous grafts and the choice of the best available conduits are of great importance at the first reoperation and may prevent a second reoperation. (J Thorac CardiovasC SuRg 1994;107:684-9)

L. Noyez, MD, ${ }^{\mathrm{a}}$ T. van der Werf, MD, ${ }^{\mathrm{b}}$ T. J. Klinkenberg, MD, ${ }^{\mathrm{a}}$ D. P. B. Janssen, MD, ${ }^{\mathrm{a}}$

G. L. Kaan, MD, and L. K. Lacquet, MD, ${ }^{\mathrm{a}}$ Nijmegen, The Netherlands

D espite the increasing number of reoperations for coronary revascularization and of studies analyzing the problems concerning this subject, only a little is known about the results of a third or fourth operation..$^{1-9}$ Of course re-reoperations are not frequent; however, it is clear that the patients who do undergo re-reoperation constitute a special group, which may be increasing in the coming years. In this report we describe our experience and early results with 16 patients who underwent a second reoperation for coronary artery-disease.

\section{Materials and methods}

Patient population. Of the 2636 patients who underwent an isolated myocardial revascularization procedure between January 1987 and December 1992 in our department, 16 patients $(0.6 \%)$ underwent a second coronary reoperation (Re-regroup). All preoperative, perioperative, and postoperative data were collected in and retrieved from the coronary databank

From the Departments of Thoracic and Cardiac Surgery and Cardi-

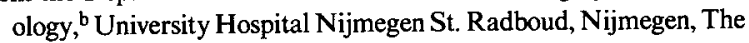
Netherlands.

Received for publication Feb. 26, 1993.

Accepted for publication Aug. 17, 1993.

Address for reprints: L. Noyez, MD, Department of Thoracic and Cardiac Surgery, University Hospital Nijmegen St. Radboud, Postbus 9101, 6500 HB Nijmegen, The Netherlands.

Copyright ${ }^{\circledR} 1994$ by Mosby-Year Book, Inc.

$0022-5223 / 94 \$ 3.00+0 \quad 12 / 1 / 50818$
“CORRAD” (Coronary Surgery Database-Radboud Hospital, Nijmegen, The Netherlands). Table I presents preoperative data of the Re-re-group and also the comparative data of the patients undergoing a first coronary reoperation ( $\mathrm{Re}$-group) and the patients undergoing a primary aorta-coronary bypass operation (P-group) during the same period. Obesity was defined as more than $10 \%$ over normal body weight and diabetes as a positive result to glucose tolerance test, peroral antidiabetic medication, or insulin dependency. Hypertension was defined as a systolic blood pressure higher than $160 \mathrm{~mm} \mathrm{Hg}$ or a diastolic pressure exceeding $100 \mathrm{~mm} \mathrm{Hg}$. Hyperlipidemia was defined as a cholesterol level greater than $6.4 \mathrm{mmol} / \mathrm{L}$ or triglyceride level greater than $2 \mathrm{mmol} / \mathrm{L}$. Poor left ventricular function was noted when ejection fraction was below $0.35 \%$.

The clinical indication for a second reoperation in all patients was angina satisfying criteria for at least New York Heart Association (NYHA) class III despite medical therapy with $\mathrm{Ca}^{++}$-entry blockers, nitrates, and $\beta$-blockers. Eleven patients were in NYHA class III and five in NYHA class IV. Further analysis of these patients showed that 12 of the 16 patients had a "good," not-replaced venous graft to the left anterior descending coronary artery (LAD) at the first reoperation. Three of these 12 patients had an anterior myocardial infarction between the first and the second reoperation. Thallium exercise testing showed that in 10 of the 12 the ischemia was located in the anterior wall.

The angiographic indications for the first and the second reoperations are summarized in Table II. Venous grafts were only considered to be good when angiograms showed no abnormalities.

Surgical technique. The sternum was longitudinally opened with an oscillating saw and the aorta and right atrium were dissected free. Subsequently, one or both internal mammary 
Table I. Preoperative variables

\begin{tabular}{|c|c|c|c|c|c|c|}
\hline \multirow[b]{2}{*}{ Variables } & \multicolumn{2}{|c|}{ Re-re-group } & \multicolumn{2}{|c|}{ Re-group } & \multicolumn{2}{|c|}{$P$-group } \\
\hline & $\mathrm{n}=16$ & $\%$ & $\mathrm{n}=258$ & $\%$ & $\mathrm{n}=2362$ & $\%$ \\
\hline Sex (male/female) & $13 / 3$ & & $167 / 91$ & & $1651 / 711$ & \\
\hline \multicolumn{7}{|l|}{ Age at primary op. (yr) } \\
\hline Mean \pm SD & $49 \pm 9$ & & $52 \pm 8$ & & $64 \pm 9$ & \\
\hline Range & $32-67$ & & $33-74$ & & $31-83$ & \\
\hline \multicolumn{7}{|l|}{ Age at reop. I (yr) } \\
\hline Mean \pm SD & $52 \pm 9$ & & $60 \pm 9$ & & & \\
\hline Range & $34-76$ & & $38-79$ & & & \\
\hline \multicolumn{7}{|l|}{ Age at reop. II (yr) } \\
\hline Mean \pm SD & $60 \pm 7$ & & & & & \\
\hline Range & $46-78$ & & & & & \\
\hline Obesity & 6 & 36 & 122 & 47 & 690 & 30 \\
\hline Diabetes & 5 & 31 & 58 & 22 & 269 & 12 \\
\hline Hypertension & 10 & 62 & 192 & 74 & 1086 & 46 \\
\hline Hyperlipidemia & 6 & 36 & 170 & 66 & 993 & 42 \\
\hline Smoking & 11 & 68 & 214 & 83 & 1892 & 80 \\
\hline Family history & 12 & 75 & 228 & 88 & 1748 & 74 \\
\hline Per. vasc. atheroscl. & 6 & 36 & 90 & 34 & 459 & 20 \\
\hline Poor LV function & 6 & 36 & 57 & 22 & 117 & 5 \\
\hline \multicolumn{7}{|l|}{ Myocardial infarction } \\
\hline Previous primary op. & 6 & 36 & 162 & 63 & 1289 & 54 \\
\hline Between primary and reop. I & 6 & 36 & 50 & 19 & & \\
\hline Between reop. I and II & 5 & 31 & & & & \\
\hline
\end{tabular}

Op., Operation; $S D$, standard deviation; reop. $I$, first reoperation; reop. $I I$, second reoperation; per. vasc. atherosc., peripheral vascular atherosclerosis; $L V$, left ventricular.

arteries (IMAs) were harvested synchronously with the necessary length of saphenous vein. After adequate heparinization was achieved the ascending aorta was cannulated and a two-stage cannula was inserted into the right atrium for venous return. A left ventricular vent was inserted through the right superior pulmonary vein. The patient was first cooled to a core temperature of $30^{\circ} \mathrm{C}$ and the heart was further dissected free. Then the patient was further cooled to a core temperature between $26^{\circ} \mathrm{C}$ and $28^{\circ} \mathrm{C}$ and slushed ice was used as topical cooling. Myocardial protection during aortic crossclamping was accomplished with infusion of cold $\left(4^{\circ} \mathrm{C}\right) \mathrm{St}$. Thomas' Hospital cardioplegic solution until asystole occurred and was maintained by reinfusion of solution, $100 \mathrm{ml} / \mathrm{m}^{2}$, every 25 to 30 minutes or less as needed in 14 of the 16 patients. In nine patients cardioplegic solution was delivered retrogradely by means of a coronary sinus cannula ${ }^{10}$ and in five the solution was delivered anterogradely. Intermittent aortic crossclamping was used in two patients.

At the initial and the first reoperation only venous grafts were used. At the second reoperation in 14 of 16 patients an IMA was used as a graft-in six patients unilaterally and in eight bilaterally, either as a single or as a sequential graft. Nineteen (64\%) of the 36 distal anastomoses were done with an IMA.

The mean bypass time was $156 \pm 32$ minutes (range 90 to 230 minutes), and the mean duration of aortic crossclamping was $72 \pm 14$ minutes (range 35 to 122). There was a mean of $2.0 \pm 0.7$ grafts (range 1 to 3 ) and a mean of $3.3 \pm 1.7$ distal anastomoses (range 1 to 6 ).

Patient follow-up. Postoperative data were retrieved from the coronary artery surgery databank "CORRAD," supplemented with follow-up information from cardiologists and by telephone interview with the patients or family.
Table II. Angiographic indication for reoperation

\begin{tabular}{lcc}
\hline & \multicolumn{2}{c}{ Re-re-group } \\
\cline { 2 - 3 } Indication & $\mathrm{n}=16$ & $\%$ \\
\hline First reoperation & 7 & 44 \\
PA & 2 & 12 \\
GF & 7 & 44 \\
PA and GF & & \\
Second reoperation & 0 & 0 \\
PA & 12 & 75 \\
GF & 4 & 25 \\
PA and GF & & \\
\hline
\end{tabular}

$P A$, Progression of atherosclerosis in native coronary vessels; $G F$, graft failure.

\section{Results}

There was no hospital mortality. Four patients had low cardiac output syndrome (a dopamine dosage $>4 \mu \mathrm{g} / \mathrm{min}$ for at least 12 hours), and three patients needed intraaortic balloon pump support. Four patients had a perioperative myocardial infarction, defined as new postoperative $\mathrm{Q}$-wave or $\mathrm{T}$-wave changes accompanied by elevated cardiac enzyme levels. Two patients needed ventilatory support for more than 3 days. Two patients underwent reoperative for bleeding, but wound problems were not encountered.

The follow-up of the 16 patients was complete. The mean duration was $24 \pm 10$ months (range 2 to 74 


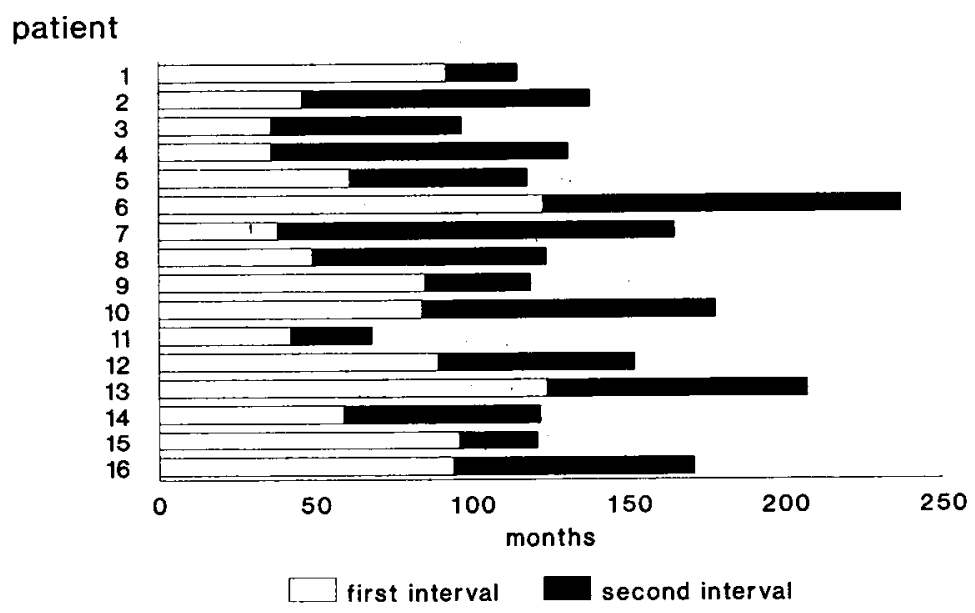

Fig. 1. Interval in months between initial operation and first reoperation (first interval) and between first and second reoperations (second interval).

Table III. Angiographic findings of the grafts

\begin{tabular}{|c|c|c|c|c|c|}
\hline & $L A D(-D)$ & $C X$ & $R C$ & Total & $\%$ \\
\hline \multicolumn{6}{|l|}{ First reoperation } \\
\hline Patent & 12 & 4 & 1 & 17 & 57 \\
\hline Stenosis $<50 \%$ & 1 & 1 & 1 & 3 & 10 \\
\hline Stenosis $\geq 50 \%$ & 2 & 2 & 2 & 6 & 20 \\
\hline Occluded & & & 4 & 4 & 13 \\
\hline Total No. & 15 & 7 & 8 & 30 & 100 \\
\hline \multicolumn{6}{|l|}{ Second reoperation } \\
\hline \multicolumn{6}{|l|}{ UCGNR } \\
\hline Patent & 2 & 0 & 0 & 2 & 12 \\
\hline Stenosis $<50 \%$ & 3 & 1 & 0 & 4 & 24 \\
\hline Stenosis $\geq 50 \%$ & 4 & 2 & 0 & 6 & 35 \\
\hline Occluded & 3 & 1 & 1 & 5 & 29 \\
\hline Total No. & 12 & 4 & 1 & 17 & 100 \\
\hline \multicolumn{6}{|l|}{ NG-first reoperation } \\
\hline Patent & 5 & 5 & 4 & 14 & 45 \\
\hline Stenosis $<50 \%$ & 1 & 1 & 2 & 4 & 17 \\
\hline Stenosis $\geq 50 \%$ & 1 & 5 & 1 & 8 & 27 \\
\hline Occluded & 0 & 2 & 1 & 3 & 11 \\
\hline Total No. & 7 & 14 & 8 & 29 & 100 \\
\hline
\end{tabular}

$L A D$, Left anterior descending coronary artery; $D$, diagonal branch; $C X$, circumflex coronary artery; $R C$, right coronary artery; UCGNR, uncompromised grafts not replaced at the first reoperation; $N G$, new grafts constructed at the first reoperation.

months). Three patients died during this period of cardiac-related causes. Interesting is that those three patients had a perioperative myocardial infarction, with a postoperative low cardiac output syndrome, and two of them needed intraaortic balloon pump support after operation. Among the 13 other patients, seven improved one NYHA class, four improved more than one NYHA class, and in two patients there was no relief of the symptoms.

Fig. 1 shows the interval between the primary operation and the first reoperation (mean $69 \pm 30$ months) and between the first and the second reoperations (mean $69 \pm 31$ months) for each patient. At the first reoperation $8(50 \%)$ of the 16 patients received supplementary venous grafts; $5(33 \%)$ of 16 received supplementary grafts and replacement of atherosclerotic grafts. However, the progression of atherosclerosis in the native coronary artery system was prominent in this group. The fate of the constructed grafts is summarized in Fig. 2. Of the 30 constructed grafts at the initial operation, $17(56 \%)$ were considered to be good and were not replaced, 13 were 


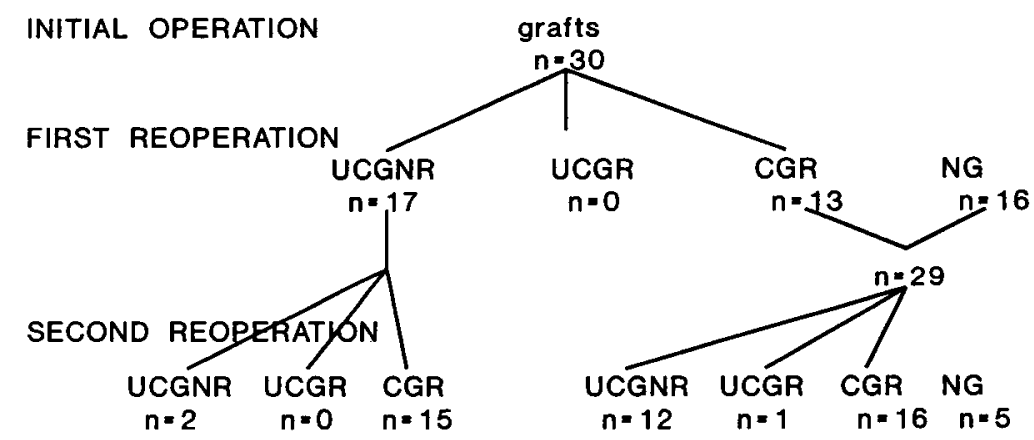

Fig. 2. Fate of grafts constructed at initial operation and first reoperation. $U C G N R$, Uncompromised grafts not replaced; $U C G R$, uncompromised grafts replaced; $C G R$, compromised grafts replaced; $N G$; new grafts to not previously bypassed coronary arteries.

replaced, and 16 new grafts were constructed at the first reoperation. At the second reoperation, only two of the initial constructed grafts were considered to be good and left in place: of the 29 constructed grafts at the first reoperation, $13(44 \%)$ were considered to be good, however, because of damage to one of these grafts, only 12 were not replaced, so that 17 grafts were replaced and 5 new grafts were constructed at the second reoperation. Table III shows the angiographic findings of the grafts, and Table IV shows the individual fate of the initial constructed grafts and the sites they were grafted to.

\section{Discussion}

Despite the increasing prevalence of reoperation for coronary artery disease and the multiple studies elucidating the operative risks, reoperation is still associated with a higher mortality and morbidity rate than the initial procedure. ${ }^{1-9}$ The higher-risk character of second reoperations is stressed by Loop, Lytle, and Cosgrove ${ }^{11}$ in an editorial in which they stated that a second reoperation is possible, but that the associated risk is higher than that of the first reoperation and that it frequently is an undesirable event for surgeon and patient. Also, the fact that in larger studies analyzing perioperative morbidity and mortality of reoperations patients with three or more coronary artery operations were excluded shows that they must be considered as a special group. ${ }^{1,3}$

The limited number of patients undergoing a second coronary artery reoperation and the complexity of factors influencing the results are of course restricting factors in analyzing the problem of these patients. Therefore in our report we did not make comparative statistical analyses with patients having primary operations or with patients undergoing a first reoperation.

Our prevalence of second reoperations and the young ages of these patients at the initial operation correlate with other studies. ${ }^{6-9}$ The prevalence of the registered risk factors is comparable between the Re-re-group, the
Table IV. Review of the individual fate of the grafts constructed at the initial operation

\begin{tabular}{|c|c|c|c|c|}
\hline Patient & $\begin{array}{l}\text { No. of } \\
\text { grafts }\end{array}$ & $\begin{array}{l}\text { Distal } \\
\text { anast. }\end{array}$ & $\begin{array}{c}U C G N R \\
\text { reop. } I\end{array}$ & $\begin{array}{l}\text { UCGNR } \\
\text { reop. II }\end{array}$ \\
\hline \multirow[t]{3}{*}{1} & 3 & LAD & LAD & \\
\hline & & $\mathrm{CX}$ & $\mathrm{CX}$ & \\
\hline & & $\mathrm{RC}$ & & \\
\hline 2 & 1 & LAD-D & LAD-D & LAD-D \\
\hline \multirow[t]{3}{*}{3} & 3 & LAD & & \\
\hline & & $\mathrm{CX}-\mathrm{CX}$ & & \\
\hline & & $\mathrm{RC}$ & & \\
\hline \multirow[t]{2}{*}{4} & 2 & LAD & LAD & \\
\hline & & $\mathrm{RC}$ & & \\
\hline \multirow[t]{2}{*}{5} & 2 & LAD & LAD & \\
\hline & & $\mathrm{CX}$ & $\mathrm{CX}$ & \\
\hline 6 & 1 & LAD & LAD & LAD \\
\hline 7 & 1 & LAD-D & LAD-D & \\
\hline 8 & $i$ & $\mathrm{RC}$ & RC & \\
\hline \multirow[t]{2}{*}{9} & 2 & LAD & LAD & \\
\hline & & $\mathrm{RC}$ & & \\
\hline 10 & 1 & LAD & LAD & \\
\hline 11 & 1 & LAD & & \\
\hline \multirow[t]{2}{*}{12} & 2 & LAD-D & & \\
\hline & & $\mathrm{CX}$ & & \\
\hline \multirow[t]{2}{*}{13} & 2 & LAD-D-D & LAD-D-D & \\
\hline & & $\mathrm{RC}$ & & \\
\hline \multirow[t]{2}{*}{14} & 2 & LAD & LAD & \\
\hline & & $\mathrm{CX}$ & $\mathrm{CX}$ & \\
\hline \multirow[t]{3}{*}{15} & 3 & LAD & LAD & \\
\hline & & $\mathrm{CX}-\mathrm{CX}$ & & \\
\hline & & $\mathrm{RC}$ & & \\
\hline \multirow[t]{3}{*}{16} & 3 & LAD & LAD & \\
\hline & & $\mathrm{CX}$ & $\mathrm{CX}$ & \\
\hline & & $\mathrm{RC}$ & & \\
\hline
\end{tabular}

Distal anast., Site of the distal anastomosis; UCGNR reop. I, uncompromised grafts not replaced at the first reoperation; UCGNR REOP. II, uncompromised grafts constructed at the initial operation and not replaced at the second reoperation; $D$, diagonal branch; $C X$, circumflex coronary artery; $R C$, right coronary artery.

Re-group, and the P-group. However, it must be noted that only "good candidates" were accepted for a second reoperation. That between each operation nearly one third of the patients had a new myocardial infarction 
corresponds with the idea that between the initial and the first reoperation nearly one third of the patients lose previously normal left ventricular function. ${ }^{11}$ That only $36 \%$ of the Re-re-group had a myocardial infarction before the initial operation has certainly also to do with the selection of the "good candidates." The change in angiographic indication for the first and the second reoperation conforms with the global evolution of the angiographic indication in reoperations from progression of atherosclerosis in the native coronary vessels to venous graft failure and a combination of both. ${ }^{1,3}$ The mean interval $(69 \pm 30$ months) between the initial operation and the first reoperation in our patients is comparable with a mean interval of $72 \pm 44$ months for the reoperations between 1979 and 1981 described by Lytle $^{1}$ and Loop ${ }^{3}$ and their colleagues. The mean interval of $68 \pm 31$ months between the first and the second reoperations in our patients seems relatively short. However, the interval between the initial operation and the second reoperation was $141 \pm 41$ months, and this is comparable with the increasing of the intervals during the initial operation and the reoperations described by Loop and associates. ${ }^{3}$ The mean intervals between the initial operation and the first reoperation and between the first and the second reoperations of our patients were comparable ( 5 to 6 years).

The clinical indication for a new coronary angiography (and reoperation) was the same. At the first reoperation angiography showed that the symptoms were mostly caused by progression of the pathologic conditions, but also that only $57 \%$ of the initial constructed grafts were good. At the second reoperation, also, half of the grafts constructed at the first reoperation were diseased. The reduction of the patency of $50 \%$ for venous grafts over 5 years has been described. ${ }^{12,13}$ This global reduction of the venous patency rate is also found when we evaluate the graft patency and the site they were grafted to. The prevalence of occlusion of venous grafts to the right coronary artery constructed at the initial operation is probably because most of these grafts were constructed to the proximal right coronary artery and this coronary artery showed new abnormalities at the distal site, resulting in a flow obstruction through the previously constructed venous graft. The superior patency of the venous grafts to the LAD is known ${ }^{12,13}$ and also clear in our angiographic evaluation; however, at the time of the second reoperation, 10 of $12 \mathrm{LAD}$ grafts were diseased. This angiographic finding, in combination with the clinical findings (anterior infarction, ischemia) of the patients with a notreplaced LAD graft, suggests that a second reoperation could have been prevented if the LAD graft was replaced at the first reoperation.

This confirms of course the statement that vein grafts in place for more than 5 years should be replaced during reoperation, regardless of the reason for reoperation, ${ }^{12}$ especially vein grafts to the anterior descending coronary artery because they are prognostically more dangerous than native vessel atherosclerosis. ${ }^{14,15}$ However, it must be clear that replacing open venous grafts calls for extreme care, because of the risk of intraoperative atheroembolization into the coronary microcirculation resulting in myocardial infarction during dissection of the distal anastomosis. ${ }^{16}$ Proximal ligation of those veins before manipulation does not totally prevent this risk, inasmuch as embolization of debris is possible even with occluded venous grafts. ${ }^{17}$

The IMA is the graft of choice also in reoperation, and when used in reoperation it will possibly reduce the need for a second reoperation. ${ }^{1,3,11,18,19}$ Although the smaller lumen of the IMA results in a limited blood flow capacity, measurements of flow characteristics of the IMA in dogs demonstrated that this graft could match or exceed the flow rate required by the myocardium. ${ }^{20,21}$ The situation in reoperations, however, is different, certainly when there is a vein graft to the LAD that is not totally occluded. ${ }^{15}$

The fact that there was no operative mortality in this study is of course relative, because the number of patients was small and only "good candidates" were accepted for a second reoperation. The morbidity, prevalence of perioperative myocardial infarction, need for intraaortic balloon pump support, and need for reoperation for bleeding were somewhat high and, as in first reoperations, the morbidity was especially cardiac-related. These complication rates, however, are difficult to place into context because of the small number of patients and the lack of other series. The problem of effective myocardial protection, embolization of debris from atherosclerotic vein grafts, difficulties with vessel identification, and lack of bypass conduits resulting in an imcomplete revascularization will certainly be even more important than in first reoperations. ${ }^{1,3}$

Our follow-up shows three deaths, all cardiac-related and occurring in the first 6 months after the operation. The three patients had a difficult postoperative recovery and they never did well after the operation, whereas the other patients are doing well. Eighty-four percent of our patients received IMA grafts and because the postoperative patency rate of an isolated IMA graft in reoperation is comparable with the results in primary revascularization, we suppose that the long-term follow-up may be excellent. ${ }^{13}$

In conclusion, a second reoperation for coronary atherosclerosis is possible; however, the fact that the first reoperation is done mostly for progression of the athero- 
sclerosis in the native system and the second for graft failure suggests that, at the first reoperation, the choice of the best conduits available and replacement of even patent venous grafts (to the LAD) are essential to avoid a second reoperation.

\section{REFERENCES}

1. Lytle BW, Loop FD, Cosgrove DM, et al. Fifteen hundred coronary reoperations. J THORAC CARDiovasc SuRG 1987;93:847-59.

2. Loop FD. A 20-year experience in coronary artery reoperation. Eur Heart J 1989;10(suppl H):78-84.

3. Loop FD, Lytle BW, Cosgrove DM, et al. Reoperation for coronary atherosclerosis: changing practice in 2509 consecutive patients. Ann Surg 1990;212:378-86.

4. Cameron A, Kemp HG Jr, Green GE. Reoperation for coronary artery disease: 10 years of clinical follow-up. Circulation 1988;78(Suppl):I158-61.

5. Hjelms E, Kjaergard H. Repeat coronary artery bypass grafting. Scand J Thorac Cardiovasc Surg 1991;25:133-5.

6. Owen EW Jr, Schoettle GP Jr, Marotti AS, Harrington OB. The third time coronary artery bypass graft: Is the risk justified? J Thorac Cardiovasc Surg 1990;100:31-5.

7. Merrill WH, Elkins CG, Stewart JR, First WH, Bender HW. Third-time coronary artery bypass grafting: midterm results. Ann Thorac Surg 1993;55:582-5.

8. Brenowitz JB, Johnson WD, Kayser KL, Saedi SF, Dorros $\mathrm{G}$, Schley L. Coronary artery bypass grafting for the third time or more. Circulation 1988;78(Suppl):I666-70.

9. Accola KD, Craver JM, Weintraub WS, Guyton RA, Jones EL. Multiple reoperative coronary artery bypass grafting. Ann Thorac Surg 1991;52:738-44.

10. Chitwood WR. Retrograde cardioplegia: current methods. Ann Thorac Surg 1992;53:352-5.

11. Loop FD, Lytle BW, Cosgrove DM. Bilateral internal thoracic artery grafting in reoperations. Ann Thorac Surg 1991;52:3-4.
12. Marshall WG Jr, Saffitz J, Kouchoukos NT. Management during reoperation of aortocoronary saphenous vein grafts with minimal atherosclerosis by angiography. Ann Thorac Surg 1986;42:163-7.

13. Grondin CM, Campeau L, Lespérance J, Enjalbert M, Bourassa MG. Comparison of late changes in internal mammary artery and saphenous vein grafts in two consecutive series of patients 10 years after operation. Circulation 1984;70(suppl 1):208-12.

14. Lytle BW, Loop FD, Goormastic M, et al. The vein graft disease: the clinical impact of stenoses in saphenous vein to coronary artery bypass grafts. J THORAC CARDIOvaSC SURG 1992;103:831-40.

15. Lytle BW, Loop FD, Taylor PC, et al. The effect of coronary reoperation on the survival of patients with stenoses in saphenous vein bypass grafts to coronary arteries. J THORAC CARDiovasc Surg 1993;105:605-14.

16. Keon WJ, Heggtveit HA, Leduc J. Perioperative myocardial infarction caused by atheroembolism. J THORAC CARDIOVASC SURG 1982;84:849-55.

17. Calhoun TR, Johnston RH, McKowen RL, Garcia-Rinaldi $R$. Retrograde coronary sinus cardioplegia in redo aortocoronary bypass [Letter]. Ann ThoracSurg 1990;49:687.

18. Galbut DL, Traad EA, Dorman MJ, et al. Bilateral internal mammary artery grafts in reoperative and primary coronary bypass surgery. Ann Thorac Surg 1991;52:20-8.

19. Noyez L, Van der Werf T, Janssen DPB, et al. Experience and early results with bilateral internal mammary artery grafting in coronary reoperations. Am J Cardiol 1992; 70:1113-6.

20. Barner HB, Naunheim KS, Willman VL, Fiore AC. Revascularization with bilateral internal thoracic artery grafts in patients with left main coronary stenosis. Eur $\mathbf{J}$ Cardiothorac Surg 1992;6:66-71.

21. Lee CN, Orszulak TA, Schaff HV, Kaye MP. Flow capacity of the canine internal mammary artery. J THORAC CARDIOVASC SuRg 1986;91:405-10. 